\title{
THERMOGRAPHIC METHOD BASED ACCELERATED FATIGUE LIMIT CALCULATION FOR STEEL X5CRNI18-10 SUBJECTED TO ROTATING BENDING
}

\author{
Adam Lipski, Ph.D. \\ University of Science and Technology in Bydgoszcz, Poland
}

\begin{abstract}
The article presents an accelerated method for fatigue limit calculation which makes use of constant temperature increase rate observed in the middle time interval of specimen fatigue loading. The examination was performed on specimens prepared from drawn rods made of corrosion resistant austenitic steel X5CrNi18-10 (1.4301) subjected to rotating bending. For comparison purposes, the fatigue limit was also calculated with the aid of the Staircase method, using 30 specimens and assuming the base number of cycles equal to 10.106. Three specimens were used for accelerated examination during which their temperature was measured with the aid of the thermographic camera CEDIP Silver $420 M$ (FLIR SC 5200). The applied loads were gradually increased until specimen damage took place. Based on the analysis of temperature changes during specimen loading, the average rate of temperature increase at successive loading stages was assessed. The obtained results were then approximated using the 2-nd order curve and its minimal value was assumed as corresponding to the fatigue limit. The performed statistic test has revealed that the fatigue limit calculated in the above way does not differ substantially from that determined using the Staircase method.
\end{abstract}

Keywords: fatigue limit; reversed bending; IR thermography; Staircase method

\section{INTRODUCTION}

The nominal stress concept based fatigue analysis is a basic element of fatigue life evaluation of structural elements, including those composing ship structures [1]. An important component of this analysis is construction of the S-N (Wöhler) curve for the examined material or structural element, and the basic parameter of this curve, in turn, is the fatigue limit. It is also an important parameter when determining the fatigue life based on cumulative damage hypotheses [2], or performing multiaxial strength criteria based calculations to assess the normal stress/shear stress relation [3] or the effect of disproportional load [4].

A standard and globally acknowledged method to determine the fatigue limit is the Staircase method (British Standard Institution - BS 3518 Methods of fatigue testing. Part 5: Guide to the application of statistics; L'association Francaise de Normalisation - NF A 03-405 Essais de Fatigue, Japan Society of Mechanical Engineers (JSME) - JSME S 002-81 Standard
Method of Statistical Fatigue Testing). This method is used for direct calculation of the average value and standard deviation of the fatigue limit [5][6][7]. However, it requires long-lasting fatigue tests performed on tens of specimens until the base number of cycles, ranging from $2 \cdot 10^{6}$ (in tests of structural elements) to $100 \cdot 106$ (when testing material properties of nonferrous metal alloys), is obtained, or the specimen is earlier damaged. For instance, when testing a single steel specimen subjected to periodic tension/compression loads (cycle asymmetry coefficient $R=1$ ) at the loading frequency $f=10 \mathrm{~Hz}$, which is a standard frequency obtained on hydraulic strength machines, the base number of $10 \cdot 106$ cycles is obtained after about 278 hours. In tests of a single steel specimen subjected to periodic bending at the loading frequency $f=100 \mathrm{~Hz}$, being a standard in machines used for rotating bending, obtaining the base number of cycles equal to 10.106 needs 28 hours. For the Staircase method this time is to be multiplied by the number of tested specimens. 
In this context, accelerated methods to determine the fatigue limit are sought which will enable both to shorten the time needed to obtain the results, and to reduce the number of specimens needed for tests. In general, the accelerated methods are expected to shorten the fatigue examination and reduce its cost, at the same time ensuring that their quality does not differ substantially from the classical methods. The group of accelerated methods includes the Locati method [8] and the method of programmed fatigue tests [9], which, however, require the information on the slope coefficient of the fatigue curve. To avoid this difficulty, the method is combined with thermographic techniques, among other approaches [10].

Attempts to improve the accuracy in determining the fatigue limit focus on seeking new methods based on physical phenomena related with the fatigue process. Since the specimen or the structural element subjected to static load [11][12][13] or dynamic load is a source of heat generated as a result of internal processes, mainly those related with plastic deformation [14] [15][16], then the methods which base on specimen temperature measurements, in particular contactless thermographic methods, are very useful for modelling the fatigue process [17].

It was Risitano who first used the thermographic method to determine the fatigue limit in 1986 [18]. Then this method was used and/or modified in [19][20][21][22], among other works. A similar idea was used when determining the fatigue limit in the Lock-In method [23][24]. In the above works the fatigue limit was calculated, as a rule, for axial loads, based on the time interval of temperature stabilisation which occurs during phase 2 of fatigue loading (fig. 1 - line A).

However, not all materials reveal the abovementioned temperature stabilisation during fatigue loading, which substantially reduces the scope of application of the already developed thermodynamic methods of accelerated fatigue limit calculation. The method presented in this paper bases on constant rate of temperature increase which is observed during phase 2 of fatigue load (fig. 1 - line B), as illustrated by the case of corrosion resistant austenitic steel X 5 CrNi18-10 subjected to rotating bending.

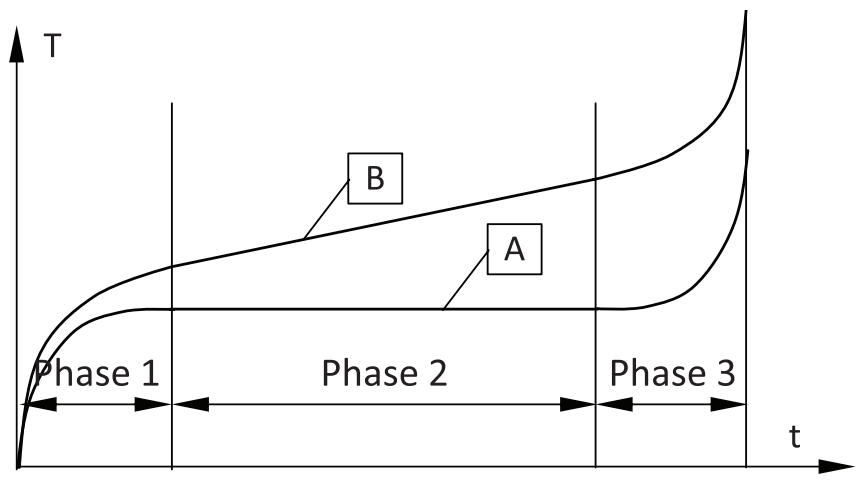

Fig. 1. Changes of temperature $T$ during fatigue test for the material which reveals temperature stabilisation (line A) or constant temperature increase rate (line B) during phase 2

\section{TEST RIG AND SPECIMENS}

Test rig. The tests were performed at the Department Laboratory for Research on Materials and Structures (certified by the Polish Centre for Accreditation - PCA AB 372) of the Faculty of Mechanical Engineering at the UTP University of Science and Technology in Bydgoszcz, on the machine for rotating bending fatigue tests (loading frequency $77 \mathrm{~Hz}$ ).

The basic component of the test rig was the thermographic camera CEDIP Silver 420M (FLIR SC5200) equipped with high-sensitivity matrix InSb cooled by Stirling pump. The basic parameters of the camera were:

- matrix resolution: $320 \times 256$ pixels,

- $\quad$ spectral range: $3.6 \div 5.0 \mu \mathrm{m}$,

- $\quad$ sensitivity: below $20 \mathrm{mK}$ (available: $8 \mathrm{mK}$ ),

- thermogram recording frequency: up to $140 \mathrm{~Hz}$ for the entire matrix (up to $25000 \mathrm{~Hz}$ in lower resolution).

The thermographic camera recorded, at the frequency of $25 \mathrm{~Hz}$, the 2D temperature distribution over the surface of the specimen subjected to rotating bending in the test machine. The image from the camera was passed via USB 2.0 interface to the PC computer with relevant software in which it was recorded, in digital form as PTW files, directly on the disc.

The software installed in the PC computer included:

- VirtualCAM, which provided two-way communication between the computer and the thermographic camera via the USB 2.0 interface,

- CIRRUS Front End, being the user's interface to control the CEDIP camera,

- $\quad$ ALTAIR, which enabled collecting, recording and advanced processing of thermographic images.

Specimens for tests. The specimens for the tests were made from drawn rods of corrosion resistant austenitic steel X5CrNi18-10 (1.4301) having the offset yield strength $\mathrm{R}_{\mathrm{p} 0.2}=706 \mathrm{MPa}$ and the tensile strength $\mathrm{R}_{\mathrm{m}}=798 \mathrm{MPa}$. The geometry of the used specimens is shown in fig. 2 , and the chemical composition of the specimen material is given in.

Tab. 1. Chemical composition of material for specimens

\begin{tabular}{|c|c|c|c|c|c|c|c|c|}
\hline & $u$ & $\stackrel{\Xi}{\Sigma}$ & $\ddot{\omega}$ & $\omega_{1}$ & $n$ & $\dot{U}$ & $\bar{z}$ & 乙 \\
\hline 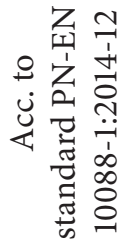 & $\begin{array}{l}\stackrel{0}{0} \\
0 \\
0 \\
\text { VI }\end{array}$ & $\stackrel{\stackrel{0}{\mathrm{~V}}}{\mathrm{~V}}$ & $\frac{\partial}{\mathrm{V}}$ & $\begin{array}{l}\text { o̊ } \\
\text { in } \\
0 \\
\dot{0} \\
\text { VI }\end{array}$ & $\begin{array}{l}\text { ¿̊ } \\
\text { in } \\
0 \\
0 \\
0 \\
\mathrm{~V}\end{array}$ & 望 & $\begin{array}{c}\stackrel{0}{1} \\
0 \\
0 \\
\infty \\
\infty\end{array}$ & 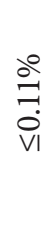 \\
\hline 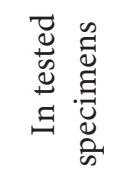 & $\stackrel{\stackrel{\circ}{0}}{\stackrel{0}{0}}$ & $\stackrel{\tilde{n}}{n}$ & $\begin{array}{l}\partial^{\circ} \\
\stackrel{0}{0} \\
\dot{0}\end{array}$ & 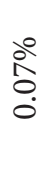 & 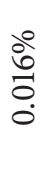 & $\begin{array}{l}\stackrel{\circ}{10} \\
\stackrel{\infty}{n} \\
\stackrel{1}{n}\end{array}$ & $\stackrel{\stackrel{\circ}{N}}{\underset{\infty}{\infty}}$ & 1 \\
\hline
\end{tabular}




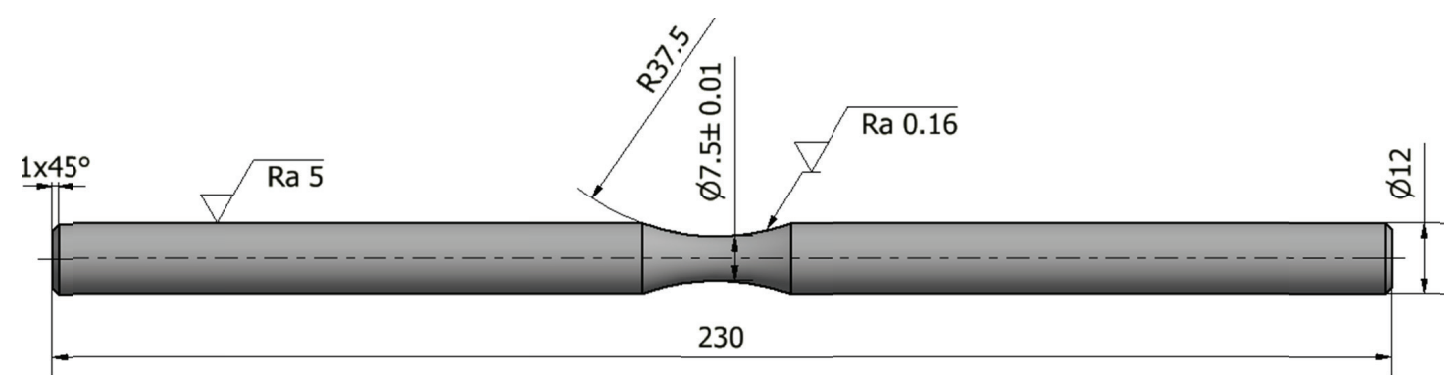

Fig. 2. Geometry of specimens used in tests

\section{DESCRIPTION AND RESULTS OF TESTS}

Results of Staircase test. The Staircase method based fatigue limit was calculated after assuming the base number of cycles equal to $\mathrm{N}_{0}=107$. Thirty specimens were used in the tests. The lowest level of stress amplitude $\mathrm{S}_{0}$ was equal to $260 \mathrm{MPa}$, while the stress increase was $\Delta S=5 \mathrm{MPa}$. The fatigue limit determined from the Dixon and Mood's relation was equal to $\mathrm{Sf}=277 \mathrm{MPa}$, with standard deviation ss $=23,6$ $\mathrm{MPa}$.

Results of accelerated method calculations. Three specimens were used in the accelerated tests. The specimens were loaded starting from the level $\mathrm{S}_{1}=230 \mathrm{MPa}$ and then gradually increasing the load, with the step $\Delta S=10 \mathrm{MPa}$, until the fatigue scrap was obtained. At each loading level, except the specimen damage level, $n_{i}=30000$ cycles were performed. collates fatigue lives obtained for successive specimens. Each tested specimen was damaged at a different loading level and, consequently, different total fatigue life was obtained for this specimen.

Tab. 2. Fatigue lives for successive specimens in accelerated tests

\begin{tabular}{|l|c|c|c|c|}
\cline { 3 - 5 } \multicolumn{2}{c|}{} & \multicolumn{3}{c|}{ Specimen } \\
\cline { 3 - 5 } \multicolumn{2}{c|}{} & no. 1 & no. 2 & no. 3 \\
\hline Fatigue failure level & $i$ & 18 & 17 & 16 \\
\hline Failure stress, MPa & $S_{k}$ & 400 & 390 & 380 \\
\hline Total fatigue life, cycle & $N_{c}$ & 518400 & 487300 & 457600 \\
\hline
\end{tabular}

The results of thermographic measurements are shown in fig. 3 and fig. 4 . fig. 3 shows temperature changes recorded on the surfaces of successive specimens during the entire test cycle, while fig. 4 presents specimen surface temperature change during the accelerated test, broken down by particular loading levels. We can notice that for all recorded loading levels, the time interval corresponding to the accelerated specimen temperature increase (phase 1 in Fig. 1) is followed by the time interval of stable temperature increase (phase 2 for curve B in Fig.1).

\section{ANALYSIS OF TEST RESULTS}

Fig. 5 shows specimen surface temperature increase rates corresponding to particular loading levels. In these diagrams, the results corresponding to the final (destroying) level of loading are omitted, as their values differ substantially from the remaining data. We can notice that the presented results have the minimum which can be related with the fatigue limit. In the vicinity of this minimum other processes connected with material degradation remarkably affect the energy balance of the entire specimen, as a result of which smaller part of it is involved in generating temperature increase. After exceeding the fatigue limit, the temperature increase rate becomes higher, which can be related with much larger plastic deformations.

a)

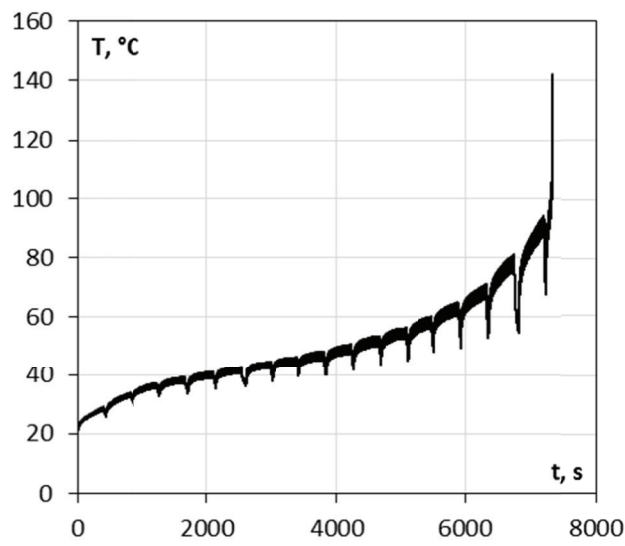

Fig. 3a. Change of temperature $T$ of specimen surface during accelerated test for specimen $1(a), 2(b)$, and $3(c)$

b)

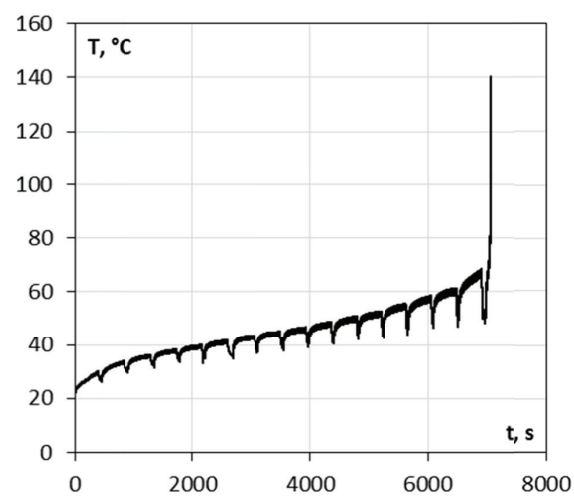

Fig. 3b. Change of temperature T of specimen surface during accelerated test for specimen $1(a), 2(b)$, and $3(c)$ 
c)

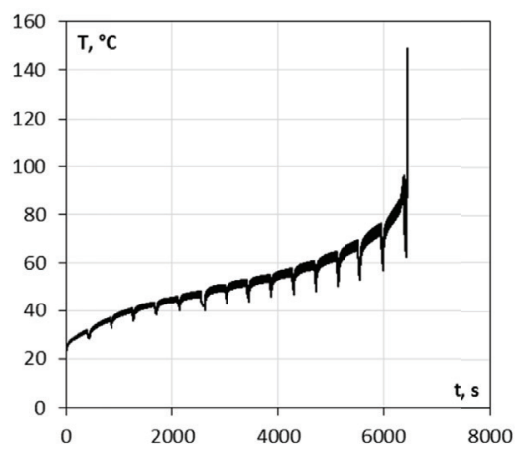

Fig. 3. Change of temperature $T$ of specimen surface during accelerated test for a)

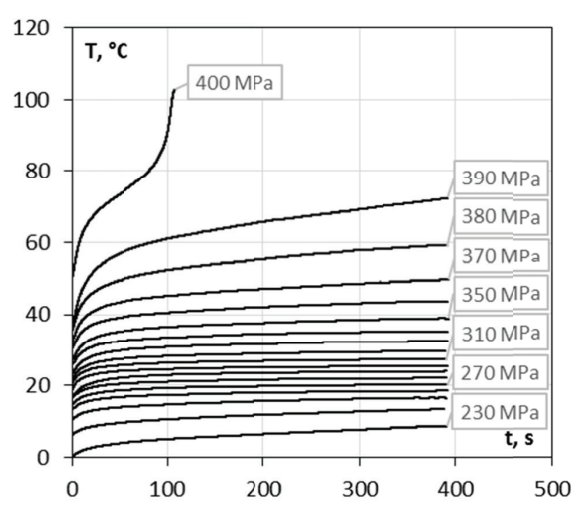

b)

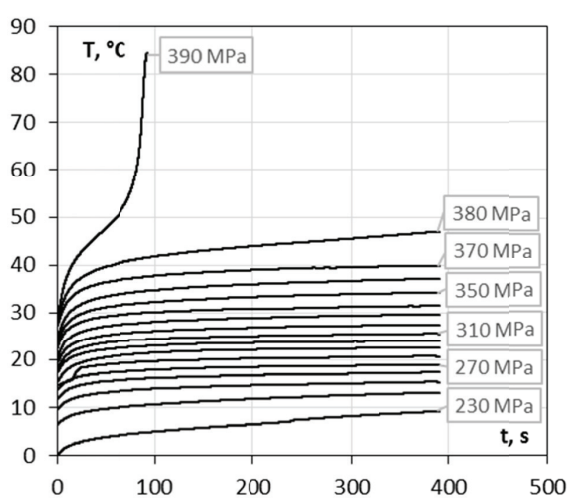

c)

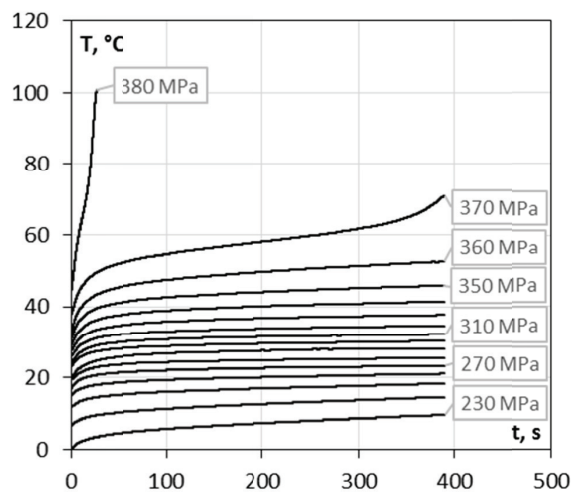

Fig. 4. Change of temperature $T$ of specimen surface during accelerated test for particular loading levels of specimen $1(a), 2(b)$, and $3(c)$ a)

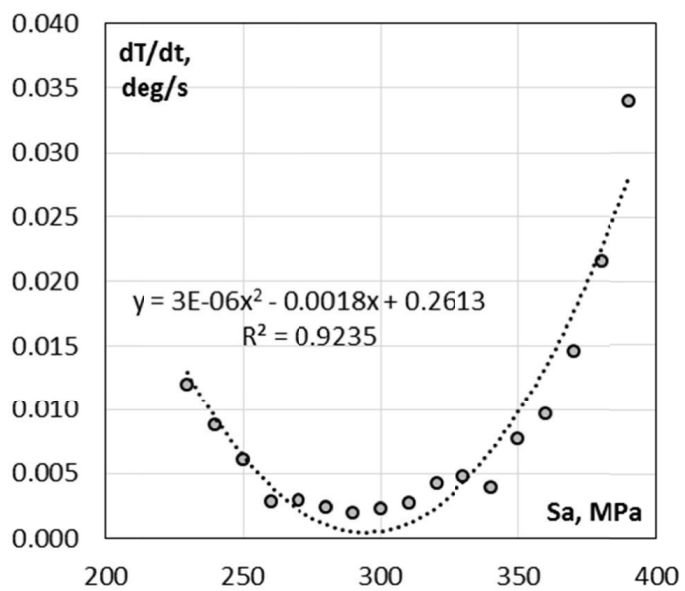

b)

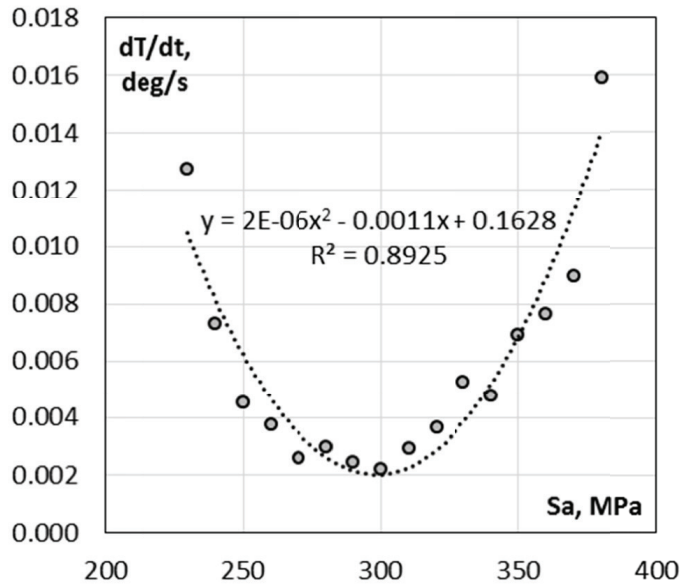

c)

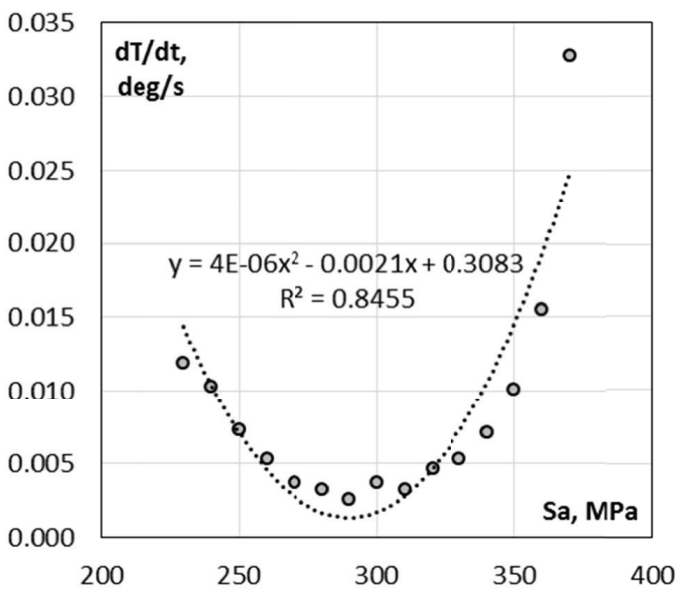

Fig. 5. Change of specimen surface temperature increase rate $d T / d t$ during accelerated test for specimen $1(a), 2(b)$, and $3(c)$

The results of examination were approximated using the $2^{\text {nd }}$-order function, omitting the value for the last (destroying) loading level. The minimum of the function obtained in the above way was interpreted as the fatigue limit (Tab. 3). 
Tab. 3. Fatigue limits for particular specimens in accelerated tests

\begin{tabular}{|l|c|c|c|c|}
\cline { 3 - 5 } \multicolumn{2}{c|}{} & \multicolumn{3}{c|}{ Specimen } \\
\cline { 3 - 5 } \multicolumn{2}{c|}{} & no. 1 & no. 2 & no. 3 \\
\hline \multirow{2}{*}{ Fatigue limit, $\mathrm{MPa}$} & $S_{f r}$ & 294.4 & 298.4 & 289.9 \\
\cline { 3 - 5 } & & \multicolumn{3}{c|}{$294.2 \pm 4.8$} \\
\hline
\end{tabular}

Although each examined specimen was damaged at different loading level and reached different total fatigue life, the fatigue limits determined in the above way do not differ substantially from each other.

The results of examination of these three specimens have made the basis for determining the average value of the fatigue limit for the accelerated method $S_{f r}=294.2 \mathrm{MPa}$ and the standard deviation for the test series $s_{s r}=4.2 \mathrm{MPa}$. Due to small number of results, the unbiased estimator of standard deviation obtained as $\hat{\sigma}=s_{s r} / c_{4}=4.8 \mathrm{MPa}$, where the value of the coefficient $c_{4}=0.8862$ for $n=3$ specimens, was assumed as the measure of standard deviation.

The level of coincidence between the fatigue limit values obtained from the accelerated method and from the Staircase method was checked using the statistical test for the average value of the population at the assumed significance level $\alpha=0.05$ and $n=3$. After adopting the value $\mathrm{m} 0=277.0 \mathrm{MPa}$ obtained from the Staircase method as the hypothetical fatigue limit and assuming the normal distribution of the fatigue limit $\mathrm{N}(277.0 ; 23.6)$, the zero hypothesis was formulated about equality of the fatigue limit obtained using the accelerated method $m=294.2 \mathrm{MPa}$ in the form

$$
\mathrm{H}_{0}: m=m_{0}
$$

against the alternative hypothesis

$$
\mathrm{H}_{1}: m>m_{0} .
$$

The value of the test statistics is

$$
t=\frac{m-m_{0}}{s} \cdot \sqrt{n}=1.26
$$

The critical value for the right-hand critical area $t_{\alpha}=1.64$ Since the inequality

$$
t<t_{\propto}
$$

holds, there is no reason to reject the zero hypothesis $\mathrm{H}_{0}$ about equality of the fatigue limits assessed using the accelerated thermographic method and the Staircase method.

\section{CONCLUSIONS}

The presented accelerated thermographic method makes it possible to shorten fatigue tests and limit the number of examined specimens, which substantially reduces examination costs, at the same time ensuring that the obtained results do not differ statistically from those obtained using the long-lasting Staircase method.
Based on the tests performed for steel X5CrNi18-10, reported in the paper, and steel $\mathrm{C} 45$, we can conclude that, compared to other presently used thermographic methods, the here proposed method enables to calculate faster the fatigue limit for cases of rotating bending of steels which reveal linear temperature increase and not stabilisation at a given level during fatigue loading, i.e. have the timetemperature characteristics close to line B in Fig. 1.

\section{ACKNOWLEDGEMENTS}

The publication financed by The Polish National Centre for Research and Development in the framework of the INNOTECH - IN-TECH program identified as the project No. INNOTECH-K3/IN3/32/227826/NCBR/14.

\section{BIBLIOGRAPHY}

1. Kozak, J., Górski, Z.: Fatigue strength determination of ship structural joints. Part I. Polish Maritime Research, No. 2(69), Vol. 18, 28-36 (2011).

2. Szala, G.: Comments on linear summation hypothesis of fatigue failures. Polish Maritime Research, No. 3(83), Vol. $21,77-85$ (2014).

3. Skibicki, D.: Experimental verification of fatigue loading nonproportionality model. Journal of Theoretical and Applied Mechanics, 45, 2, 337-348 (2007).

4. Skibicki, D.: Multiaxial fatigue life and strength criteria for non-proportional loading. Materials Testing, 48, 3 , 99-102 (2006).

5. Dixon, W.J.: The Up-and-Down Method for Small Samples. Journal of the American Statistical Association, 60, 312, 967-978 (1965).

6. Dixon, W.J., Mood, A.M.: A Method for Obtaining and Analyzing Sensitivity Data. Journal of the American Statistical Association, 43, 241, 109-126 (1948).

7. Collins, J.A.: Failure of materials in mechanical design analysis, prediction, prevention. John Wiley \& Sons, New York (1993).

8. Radaj, D.: Design and analysis of fatigue resistant welded structures. Abington, Woodhead Publishing (1990).

9. Szala, J.: Application of programmed fatigue tests to evaluating fatigue limit. Mechanika Teoretyczna i Stosowana, 3, 26, 523-539 (1988) - in Polish.

10. Lipski, A.: Determination of Fatigue Limit by Locati Method using S-N Curve Determined by Means of Thermographic Method. Solid State Phenomena, 223, 362-373 (2014). 
11. Lipski, A.: Impact of the Strain Rate during Tension Test on 46Cr1 Steel Temperature Change. Key Engineering Materials, 598, 133-140 (2014).

12. Lipski, A., Boroński, D.: Use of Thermography for the Analysis of Strength Properties of Mini-Specimens. Materials Science Forum, 726, 156-161 (2012).

13. Lipski, A., Lis, Z.: Temperature Changes Induced by the Portevin-Le Châtelier (PLC) Effect during Tensile Test Based on the Example of CuZn37 Brass. Solid State Phenomena, 224, 238-243 (2014).

14. Kaleta, J., Błotny, R., Harig, H.: Energy Stored In A Specimen Under Fatigue Limit Loading Conditions. Journal Of Testing And Evaluation, 19, 4, 326-333 (1991).

15. Audenino, A.: Correlation between thermography and internal damping in metals. International Journal of Fatigue, 25, 4, 343-351 (2003).

16. Doudard, C., Calloch, S., Hild, F., Roux, S.: Identification of heat source fields from infrared thermography: Determination of "self-heating" in a dual-phase steel by using a dog bone sample. Mechanics of Materials, 42, 1 , 55-62 (2010).

17. Lipski, A., Skibicki, D.: Variations of the Specimen Temperature Depending on the Pattern of the Multiaxial Load - Preliminary Research. Materials Science Forum, 726, 162-168 (2012).

18. La Rosa, G., Risitano, A.: Thermographic methodology for rapid determination of the fatigue limit of materials and mechanical components. International Journal of Fatigue. $22,1,65-73$ (2000).

19. Luong, M.P.: Infrared thermographic scanning of fatigue in metals. Nuclear Engineering and Design, 158, 2-3, 363-376 (1995).

20. Luong, M.P.: Fatigue limit evaluation of metals using an infrared thermographic technique. Mechanics of Materials, 28, 1, 155-163 (1998).

21. Cura, F., Curti, G., Sesana, R.: A new iteration method for the thermographic determination of fatigue limit in steels. International Journal of Fatigue, 27, 4, 453-459 (2005).

22. Galietti, U., Palumbo, D., De Finis, R., Ancona, F.: Fatigue limit evaluation of martensitic steels with thermal methods. The 12th International Conference of Quantitative Infrared Thermography, QIRT, Bordeaux (2014).

23. Li, X.D., Zhang, H., Wu, D.L., Liu, X., Liu, J.Y.: Adopting lock-in infrared thermography technique for rapid determination of fatigue limit of aluminum alloy riveted component and affection to determined result caused by initial stress. International Journal of Fatigue, 36, 1, 18-23 (2012).

24. Kordatos, E.Z., Dassios, K.G., Aggelis, D.G., Matikas, T.E.: Rapid evaluation of the fatigue limit in composites using infrared lock-in thermography and acoustic emission. Mechanics Research Communications, 54, 14-20 (2013).

\section{CONTACT WITH THE AUTHOR}

$$
\text { Adam Lipski }
$$

UTP University of Science and Technology

Faculty of Mechanical Engineering

Department Laboratory

for Research on Materials and Structures

7 Kaliskiego Street

85-796 Bydgoszcz

Poland

e-mail: Adam.Lipski@utp.edu.pl 